\title{
INEQUALITY TRENDS OF ANTENATAL CARE AMONG WOMEN IN INDONESIA 2002-2012
}

\author{
Anissa Rizkianti ${ }^{1} *$ and Tin Afifah ${ }^{1}$ \\ ${ }^{I}$ Centre for Research and Development of Public Health Efforts, National Institute of Health Research \\ Development, Indonesia
}

\begin{abstract}
Antenatal care (ANC) is a major component of maternal health services for preventing adverse pregnancy outcomes. As one of maternal health indicator for universal health coverage and Sustainable Development Goals (SDGs), it is important to monitor the distribution of the coverage among social dimension stratification. The study aims to examine inequality trends in the use of ANC services of Indonesian women aged 15-49 years based on the data from the Indonesia Demographic Health Surveys (IDHS) 2002, 2007 and 2012. Inequalities are measured using socioeconomic and demographic stratification variables such as urban-rural, mother's education and household wealth index. We also performed analysis of social determinants of health and their relationship with ANC. The trend of ANC utilization shows narrower gap according to social dimension stratification. The urban-rural difference for ANC has been reduced from 15 to 10.5 percentage points. The education-related inequality in ANC also declined nearly $40 \%$ from 2002 to 2012. A similar downward trend was observed for wealth-related inequality merely between the last two periods of survey. The trend in ANC use was entirely confounded by socioeconomic and demographic changes over time. The adjusted odds ratios for wealth quintile and education substantially decreased. A reduction in the inequality dimension through time suggests that both access and equality are improving in ANC use. Monitoring of trends needs to be continuously done among disadvantaged groups so that programs are in place for more targeted health development plans.
\end{abstract}

Keywords: antenatal care, inequality, health services, IDHS, Indonesia

\section{Introduction}

Antenatal care contributes to achieving Sustainable Development Goals by monitoring the progress on the target to reduce maternal mortality. Antenatal care (ANC) plays an important role in preventing adverse pregnancy outcomes. The importance of ANC lies in its capacity to identify risks and detect complication and educate women with information on danger signs and symptoms. It enables monitoring of the well-being of mother and fetus as well as the signs of any obstetric complications that might be treated (Chalmers et al., 2001). While the SDG strategy in expanding coverage of antenatal care (ANC) was notable in Indonesia, improvements in maternal health outcomes did not always follow. Maternal mortality ratio (MMR) remains unacceptably high representing 305 per 100,000 live births (Badan Pusat Statistik, 2016) or estimated to be nearly ten times higher than its closest neighbors, Malaysia and Brunei Darussalam (Adashi et al., 2013).

The slow pace of reduction in maternal mortality has urged many nations to begin addressing inequalities in maternal health with regard to both access to care and levels of MMR. The inequalities in maternal health care show discrepancies between the richer and poorer populations, as well as between different socioeconomic statuses (World Health Organization and Ministry of Health of Indonesia, 2017). Indonesia, across its rich and diverse ethnic groups, economic and geographical landscapes, faces challenges in addressing inequalities. While some population groups have better access to healthcare services, others are disadvantaged. Monitoring of such inequalities is therefore a fundamental part to improve access to health care of those who are disadvantaged and to ensure that Indonesia fulfills its commitment of leaving no one behind (Hosseinpoor et al., 2016). 
Within-country inequalities, however, should be described for a broad range of dimensions. At the same time, having comparable disaggregated data is essential to track inequalities at subnational level (Hosseinpoor et al., 2016). Demographic and Health Survey (DHS) serves as one of the main data sources for monitoring trends and inequalities in the use of maternal health care services due to the quality of the data and comparability over time (Corsi et al., 2012). In this study, we assess data from three consecutive Indonesia Demographic and Health Surveys (IDHSs) to explore the trends of inequalities in ANC uptake among women of reproductive age. The aim is to understand further the extent to which inequality in the coverage of ANC across socioeconomic and geographical dimension vary over time. A better understanding of the magnitude and determinants of inequalities in maternity care may help contribute to tackling these disparities and offering insights to policymakers about potential public health strategies towards a more integrated and accessible health care for all.

\section{Methods}

\section{Data sources}

This study was performed using secondary data of IDHS for the periods of 2002, 2007 and 2012. All were nationally representative household survey conducted by the Statistics Indonesia in collaboration with the National Population and Family Planning Board and the Ministry of Health of Indonesia. The dataset was retrieved from the DHS website at http://dhsprogram.com and reported in aggregate. The IDHS collects information on demographic and population, health indicators, such as contraceptive knowledge and use, maternal and child health, and nutritional status of mothers and children to assist in the country's monitoring and impact evaluation. It ensures comparability across regions, countries and time using globally standardized questionnaire.

\section{Study population}

Ever-married women age 15-49 who gave their last birth in the preceding five years of each survey were included as eligible participants.

\section{Variables}

Women who received ANC at least four visits (ANC 4+) in their last pregnancy were considered as outcome variable, recorded as a binary variable (yes/no) in the dataset. The World Health Organization (WHO) recommends that every pregnant woman should have a minimum of four focused ANC visits (Carroli et al., 2001). The inequality dimensions used in this study were as follows: educational level, wealth status and place of residence (rural/urban). Other independent variables included age at birth, birth order and subnational region. Demographic characteristics of each respondent, their housing conditions and household wealth indicators were recorded in the Household Questionnaire, whereas reproductive history and ANC information for women was captured in the Women's Questionnaire. Table 1 describes the variables and how they were defined.

\section{Statistical methods and analysis}

Trends of ANC 4+ utilization was calculated from frequency percentages by the survey years to observe the changes over time. Inequalities in ANC 4+ coverage was estimated across wealth quintiles and educational attainment and compared by using slope index of inequality as absolute measure among the subgroups of population. Slope index of inequality is a complex measure to quantify the absolute difference in predicted values of a health indicator between the most and least advantaged group, while taking into consideration the entire distribution of subgroups using an appropriate regression model (Hosseinpoor et al., 2016). It is calculated as:

$$
S I I=v_{1}-v_{0}, \text { for favorable health intervention indicators }(1)
$$


Difference was also used to measure disparities in ANC 4+ coverage between urban and rural areas. The inequality analysis was done by using WHO Health Equity Assessment Toolkit Plus (HEAT Plus) software. Database was generated from disaggregated data of IDHS which were uploaded to HEAT Plus in a specific format. Once uploaded, these data were used to explore inequalities within socioeconomic and demographic dimensions in graphs.

We generated frequency tabulation to describe socio-demographic characteristics and their distributions over three consecutive survey periods of 2007, 2012 and 2017 which were compared by using a chi-squared test. Binary logistic regression was performed to obtain both crude and adjusted odds ratio (OR) for the outcome variable using the Wald test to assess the statistical significance at $95 \%$ confidence intervals (CI), taking into account survey design (sampling weights and strata). The analysis was adjusted for all the other variables (age at birth and birth order) which might have any confounding effect. SAS Studio was used for analyzing data.

Table 1 Summary of the variables used in this study

\begin{tabular}{|c|c|}
\hline Variable name & Definition \\
\hline $\begin{array}{l}\text { ANC at least four visits } \\
\qquad(\text { ANC } 4+)\end{array}$ & $\begin{array}{l}\text { Percent of women age } 15-49 \text { with a live birth in five years period preceding the } \\
\text { survey who received antenatal care four times or more. The indicator is based } \\
\text { on standard questions that ask if, how many times, and by whom the health of } \\
\text { the woman was checked during pregnancy. }\end{array}$ \\
\hline \multirow[t]{2}{*}{ Educational level } & $\begin{array}{l}\text { The highest level of education attended by the women. It is categorized into 'no } \\
\text { education', 'primary', 'secondary' and 'higher'. }\end{array}$ \\
\hline & $\begin{array}{l}\text { 'No education' refers to women who confirmed having no formal education. } \\
\text { 'Primary' refers to women with some level of formal education or completed } \\
\text { primary education, including those with middle school. Women who completed } \\
\text { up to } 12 \text { years of formal education or those whose education ended at the upper } \\
\text { secondary/high school level consider as having 'Secondary' level. Women who } \\
\text { were having 'Higher' level are those who completed at least } 15 \text { years of formal } \\
\text { education, including those with college, polytechnic or university level studies. }\end{array}$ \\
\hline Wealth status & $\begin{array}{l}\text { Wealth status was calculated using household assets data collected from IDHS } \\
\text { surveys, such as televisions and bicycles; materials used for housing } \\
\text { construction; and types of water access and sanitation facilities. It is categorized } \\
\text { into } 5 \text { wealth quintiles: Lowest, Second, Middle, Fourth, and Highest. }\end{array}$ \\
\hline Place of residence & $\begin{array}{l}\text { The civil subdivision of a country in which the individual resides. It is } \\
\text { traditionally distinct by urban and rural. }\end{array}$ \\
\hline Age at birth & $\begin{array}{l}\text { The age of women at birth of last child. It was coded into three categories as } \\
\text { follows: }<20 \text { years, } 20-34 \text { years, } 35+\text { years. }\end{array}$ \\
\hline Birth order & $\begin{array}{l}\text { The order in which a child is born. It was coded into four categories as follows: } \\
\qquad 1,2-3,4-5 \text { and } 6+.\end{array}$ \\
\hline
\end{tabular}

\section{Results}

Table 2 shows the socio-demographic characteristics among Indonesian women age 15-49 years who had their last birth within 5 years prior to the surveys. A total of 41,945 women were included in the last three IDHS, where 2002 IDHS, 2007 IDHS and 2012 IDHS included 12,760, 14,430 and 14,782 women, respectively. The majority of women delivered their babies at the age of $20-34$ (74.2\% in 2002, $75.1 \%$ in 2007 and $74.7 \%$ in 2012). The proportion of women who gave the last birth at the younger age group decreased from $11.7 \%$ in 2002 to $9.0 \%$ in 2012. The same is true for birth order, where the proportion of multiparous $(6+)$ women declined in the year 2012 compared to 2002. The percentage of women having no education reduced by more than 50\% (4.5\% in 2002 and 1.9\% in 2012) and higher level of education was almost doubled from 6\% in 2002 to $11.9 \%$ in 2012 . However, there is no clear pattern for the percentage of women by wealth status. 
Table 2 Socio-demographic characteristics among women age 15-49 in Indonesia, IDHS 2002-2012

\begin{tabular}{|c|c|c|c|}
\hline \multirow[t]{2}{*}{ Socio-demographic characteristics } & 2002 & 2007 & 2012 \\
\hline & $\mathrm{N}=12,760$ & $\mathrm{~N}=14,403$ & $\mathrm{~N}=14,782$ \\
\hline \multicolumn{4}{|l|}{ Age at birth } \\
\hline$<20$ & 11.7 & 9.9 & 9.0 \\
\hline $20-34$ & 74.2 & 75.1 & 74.7 \\
\hline $35-49$ & 14.0 & 15.0 & 16.3 \\
\hline \multicolumn{4}{|l|}{ Birth order } \\
\hline 1 & 33.6 & 34.6 & 37.5 \\
\hline $2-3$ & 46.1 & 46.8 & 48.1 \\
\hline $4-5$ & 12.9 & 13.2 & 10.7 \\
\hline $6+$ & 7.4 & 5.4 & 3.6 \\
\hline \multicolumn{4}{|l|}{ Place of residence } \\
\hline Rural & 53.2 & 58.0 & 50.2 \\
\hline Urban & 46.8 & 42.0 & 49.8 \\
\hline \multicolumn{4}{|l|}{ Education level } \\
\hline No education & 4.5 & 3.3 & 1.9 \\
\hline Primary & 48.6 & 41.2 & 32.2 \\
\hline Secondary & 40.8 & 47.7 & 54.0 \\
\hline Higher & 6.0 & 7.9 & 11.9 \\
\hline \multicolumn{4}{|l|}{ Wealth status } \\
\hline Poorest & 22.3 & 21.4 & 20.5 \\
\hline Poorer & 19.5 & 19.9 & 19.5 \\
\hline Middle & 20.5 & 20.0 & 19.9 \\
\hline Richer & 19.6 & 19.5 & 21.0 \\
\hline Richest & 18.3 & 19.1 & 19.1 \\
\hline
\end{tabular}

\section{Trends in ANC 4+ coverage}

Figure 1 depicts an increasing trend in ANC 4+ utilization from 2002 to 2012. Proportion of utilizing ANC 4+ showed a tendency to increase overtime with the increasing status of household economic. A huge gap between poorest and richest was reported in 2002, whereas in 2012 the gap was quite decreasing. Similar to economic status, the proportion of ANC 4+ coverage by education level rose between 2002 and 2012. Although gradients of its use among women with no education and women with higher education widened from 2002 to 2007, the gradients of ANC use among women who completed primary education and those with higher education decreased from a difference of $25 \%$ point in 2002 to $16.7 \%$ point in 2012 . Furthermore, the trend in ANC 4+ utilization did not change much across type of residence, marked by confidence intervals that were still in the same range. Over the past 10 years, the urban-rural difference for ANC 4+ coverage reduced from $15 \%$ point to $10.5 \%$ point, showing that the gap between urban women and their rural counterparts was slightly narrower. 


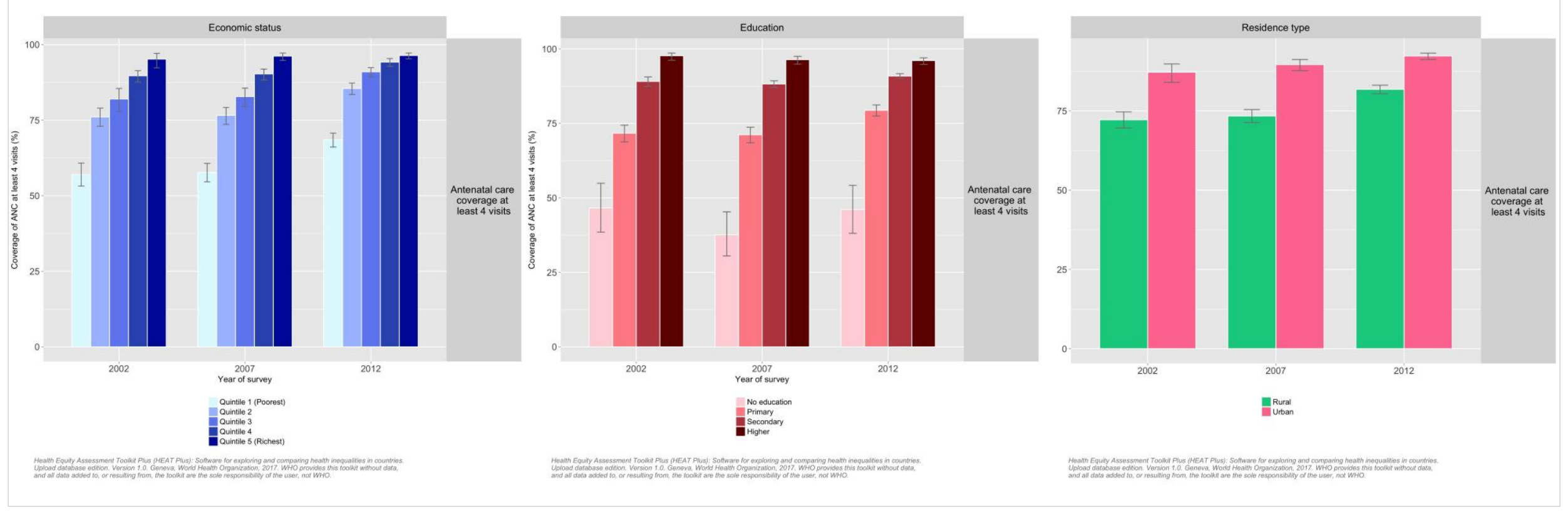

Figure 1

Trends in ANC 4+ coverage according to economic status, education and residence, 2002-2012 IDHS 
In multi variable analysis, when the effects of covariates were controlled statistically using binary logistic regression model, all socio-economic, maternal and demographic factors remained significant predictors of ANC 4+ use, except place of residence (Table 3). Among socio-economic variables, household economic status and mother's education were both powerful predictors for ANC 4+ use. However, adjusted ORs for economic status tend to decrease overtime. In 2002, mothers with higher education were almost nine times more likely (OR: 8.67; 95\% CI: 3.54-21.24) to use ANC 4+, while in 2012, the likelihood was smaller (OR: 2.57; 95\% CI: 1.45-4.57).Women with older age of birth also tend to get access to ANC 4+ services. In contrast, negative association was found between birth order and ANC 4+ use as the utilization was less common among women with birth order six or above.

Table 3 Associations between socio-demographic characteristics and antenatal care visits among women age 15-49 in Indonesia, IDHS 2002-2012

\begin{tabular}{|c|c|c|c|c|c|c|c|c|c|}
\hline \multirow{3}{*}{$\begin{array}{c}\text { Socio- } \\
\text { demographic } \\
\text { characteristics }\end{array}$} & \multicolumn{9}{|c|}{ ANC 4+ utilization } \\
\hline & \multicolumn{3}{|c|}{2002} & \multicolumn{3}{|c|}{2007} & \multicolumn{3}{|c|}{2012} \\
\hline & $\begin{array}{l}\mathrm{Adj} \\
\mathrm{OR}^{*}\end{array}$ & $95 \% \mathrm{CI}$ & $\begin{array}{c}\mathrm{P}- \\
\text { value }\end{array}$ & $\begin{array}{l}\text { Adj. } \\
\text { OR }^{*}\end{array}$ & $95 \% \mathrm{CI}$ & $\begin{array}{c}\mathrm{P}- \\
\text { value }\end{array}$ & $\begin{array}{l}\text { Adj. } \\
\text { OR }^{*}\end{array}$ & $95 \% \mathrm{CI}$ & $\begin{array}{c}\text { P- } \\
\text { value }\end{array}$ \\
\hline \multicolumn{10}{|l|}{ Age at birth } \\
\hline$<20$ & 1.00 & & & 1.00 & & & 1.00 & & \\
\hline $20-34$ & 1.74 & $\begin{array}{c}1.18- \\
2.57\end{array}$ & $0.00^{* *}$ & 1.82 & $\begin{array}{c}1.37- \\
2.43\end{array}$ & $0.00^{* *}$ & 1.58 & $\begin{array}{c}1.19- \\
2.09\end{array}$ & $0.00^{* *}$ \\
\hline $35-49$ & 2.18 & $\begin{array}{c}1.46- \\
3.27\end{array}$ & & 2.26 & $\begin{array}{c}1.55- \\
3.29\end{array}$ & & 1.80 & $\begin{array}{c}1.24- \\
2.63\end{array}$ & \\
\hline \multicolumn{10}{|l|}{ Birth order } \\
\hline 1 & 1.00 & & & 1.00 & & & 1.00 & & \\
\hline $2-3$ & 0.74 & $\begin{array}{c}0.58- \\
0.95\end{array}$ & & 0.61 & $\begin{array}{c}0.50- \\
0.74\end{array}$ & & 0.72 & $\begin{array}{c}0.59- \\
0.89\end{array}$ & \\
\hline $4-5$ & 0.44 & $\begin{array}{c}0.32- \\
0.60\end{array}$ & $0.00^{* *}$ & 0.43 & $\begin{array}{c}0.33- \\
0.55\end{array}$ & $0.00^{* * *}$ & 0.55 & $\begin{array}{c}0.41- \\
0.72\end{array}$ & $0.00^{* * *}$ \\
\hline $6+$ & 0.27 & $\begin{array}{c}0.20- \\
0.38\end{array}$ & & 0.20 & $\begin{array}{c}0.14- \\
0.29\end{array}$ & & 0.36 & $\begin{array}{c}0.24- \\
0.54\end{array}$ & \\
\hline \multicolumn{10}{|l|}{ Place of residence } \\
\hline Rural & 1.00 & & & 1.00 & & & 1.00 & & \\
\hline Urban & 0.90 & $\begin{array}{c}0.62- \\
1.30\end{array}$ & 0.57 & 1.15 & $\begin{array}{c}0.93- \\
1.43\end{array}$ & 0.20 & 1.10 & $\begin{array}{c}0.90- \\
1.34\end{array}$ & 0.35 \\
\hline \multicolumn{10}{|l|}{ Education level } \\
\hline No education & 1.00 & & & 1.00 & & & 1.00 & & \\
\hline Primary & 1.56 & $\begin{array}{c}0.95- \\
2.56\end{array}$ & & 1.66 & $\begin{array}{c}1.05- \\
2.61\end{array}$ & & 1.34 & $\begin{array}{c}0.84 \text { - } \\
2.13\end{array}$ & \\
\hline Secondary & 2.48 & $\begin{array}{c}1.58- \\
3.90\end{array}$ & $0.00^{* *}$ & 2.50 & $\begin{array}{c}1.54- \\
4.06\end{array}$ & $0.00^{* *}$ & 1.91 & $\begin{array}{c}1.20- \\
3.04\end{array}$ & $0.00^{* *}$ \\
\hline Higher & 8.67 & $\begin{array}{l}3.54- \\
21.24\end{array}$ & & 4.87 & $\begin{array}{l}2.33- \\
10.17\end{array}$ & & 2.57 & $\begin{array}{c}1.45- \\
4.57\end{array}$ & \\
\hline \multicolumn{10}{|l|}{ Wealth status } \\
\hline Poorest & 1.00 & & $0.00^{* *}$ & 1.00 & & $0.00^{* * *}$ & 1.00 & & $0.00^{* *}$ \\
\hline Poorer & 1.93 & $1.54-$ & & 1.86 & $1.54-$ & & 1.94 & $1.56-$ & \\
\hline
\end{tabular}




\begin{tabular}{ccccccc}
\hline & & 2.42 & & 2.24 & & 2.42 \\
Middle & & $1.57-$ & & $1.69-$ & & $2.41-$ \\
& 2.21 & 3.09 & 2.16 & 2.75 & 3.09 & 3.96 \\
\multirow{2}{*}{ Richer } & & $2.26-$ & & $2.43-$ & & $2.99-$ \\
& 3.20 & 4.54 & 3.21 & 4.23 & 4.11 & 5.65 \\
\multirow{2}{*}{ Richest } & & $3.03-$ & & $4.65-$ & & $4.36-$ \\
& 5.54 & 10.15 & 7.21 & 11.19 & 6.47 & 9.61 \\
\hline
\end{tabular}

\section{Trends in ANC 4+ inequalities}

Figure 2 shows the changes in inequality of ANC 4+ utilization across economic status and education level from 2002 to 2012. The following figure is the result of inequality calculation using slope index of inequality (SII) as a summary measure of inequality. The SII indicated existence of inequalities in ANC 4+ utilization for two different dimensions. As shown in the figure, the coverage of ANC 4+ has increased substantially as inequalities declined. The general downward trend for SII by economic status was seen. A reduction of SII for ANC 4+ was observed across economic status, although the value slightly increased between 2002 and 2007. The absolute inequalities in ANC 4+ across education level also declined overtime. A slight decrease of SII was observed from 2002 to 2007, but the trend was reduced sharply between 2007 and 2012. The gap between the richest and poorest varies by province (Figure 3). Most provinces in Java and Bali region has narrower gap between poorest and richest in the use of ANC 4+ over the past decade. As seen in the figure above, Jakarta, Banten and West Nusa Tenggara have successfully reduced the gap more than $65 \%$.

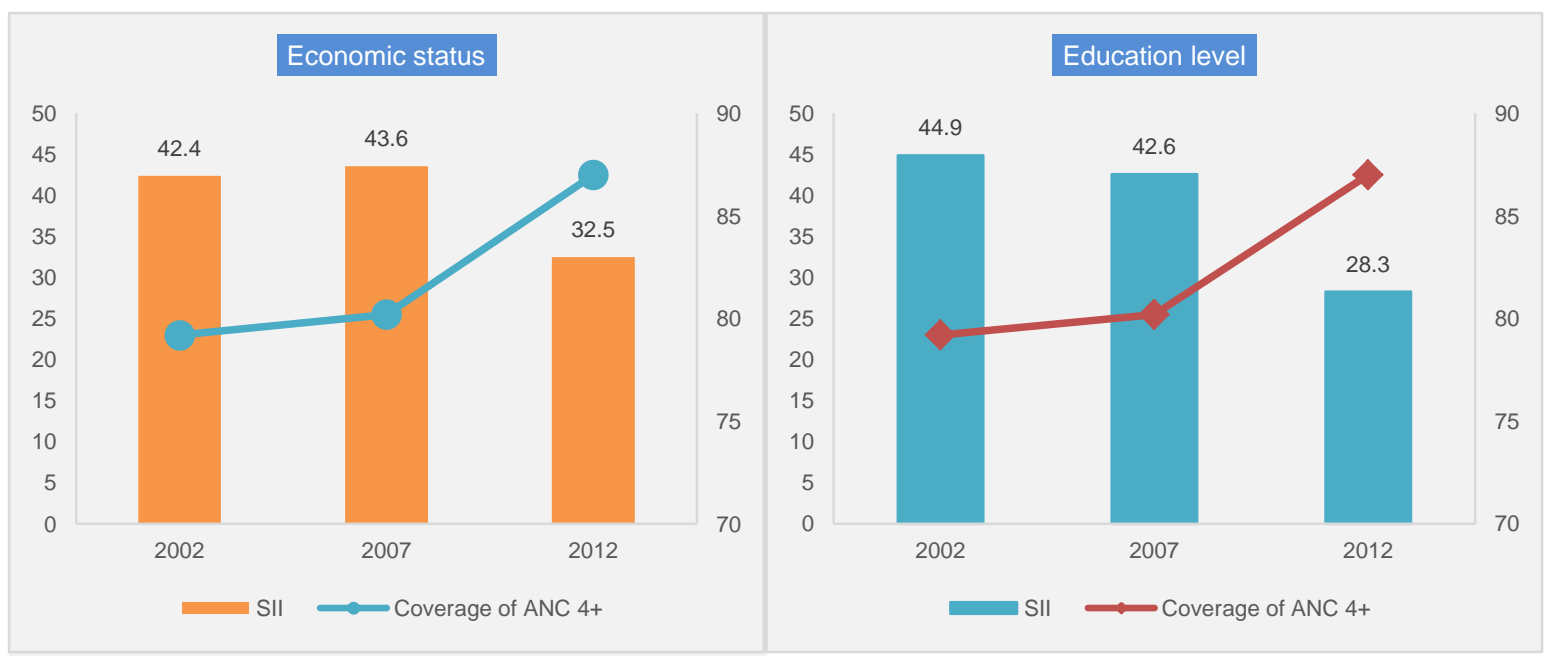

Figure 2 Inequality trends in ANC 4+ coverage across economic status, education and residence, 2002-2012 IDHS 


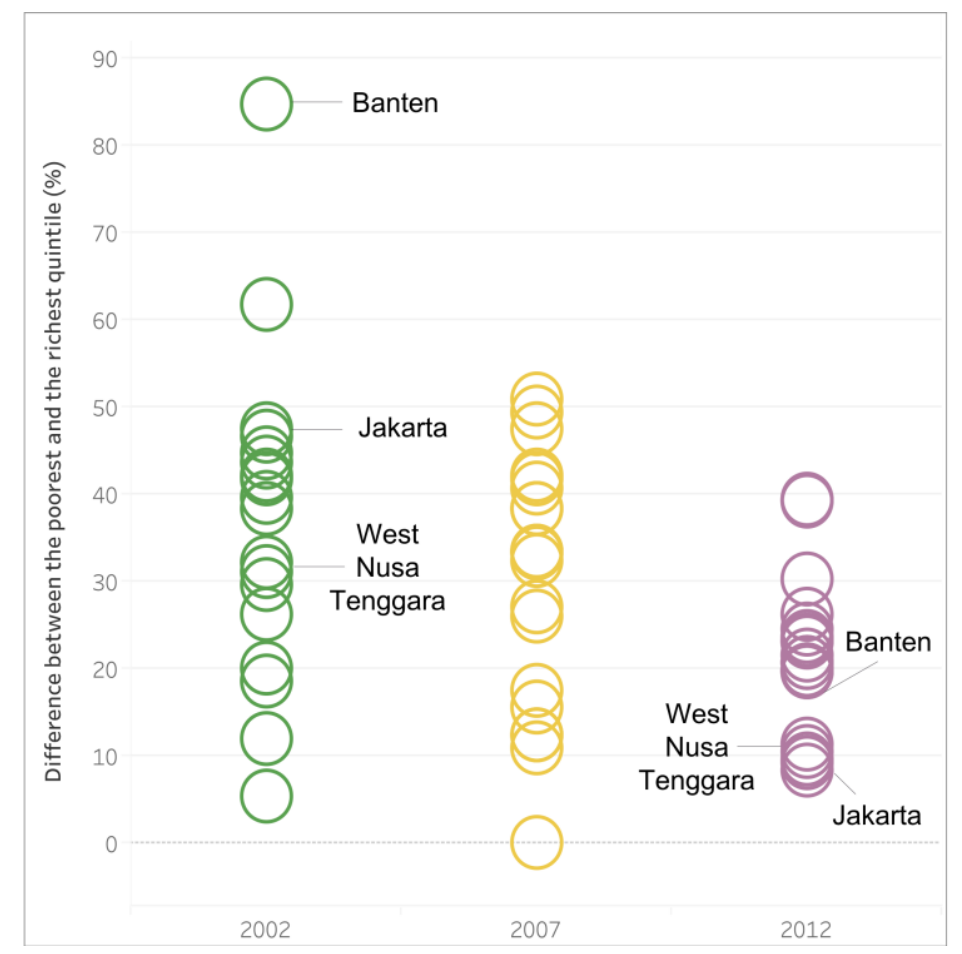

Figure 3 Inequality trends in ANC 4+ coverage across subnational region, 2002-2012 IDHS

\section{Discussion}

This study revealed that Indonesia is experiencing a substantial progress in the reduction of health inequalities and positive change in the social determinants of health over the past decade. Socioeconomic, urban-rural and geographical inequalities in ANC were particularly pressing. Utilization of ANC services has also increased, reflecting improved coverage and access. Nevertheless, women who are rich, well-educated and living in urban settings still have greater opportunity to access ANC 4+. Our findings are in line with evidence on several low and middle-income countries which reported low utilization of ANC 4+ among poor and uneducated women (Nababan et al., 2018; Rahman et al, 2017; Anwar et al, 2015; Molina et al., 2013). A systematic review identified that financial constraints are barrier for poor people in developing countries to access care. Women's education was also the best predictor of ANC visits as better educated women were more likely to receive the recommended number of ANC visits (Simkhada et al., 2008)

Reductions in the inequality of ANC 4+ services reflected substantial use among women at rural areas in Indonesia. This can be explained by the increasing role of private sector in maternal health services, especially midwives. Heywood and Choi (2010) found that among women who received antenatal care, they mostly received it from a private sector provider, such as midwife and village midwife. In Indonesia, the expansion of public and private facilities began before the 1990s. By then, the government allowed facilities to be established and staffed in many remote areas, resulting a rapid expansion of public health facilities and medical staff (Heywood and Harahap, 2009). Since decentralization in 1999, the deployment of medical professionals is in the hand of local authorities. They have focused on increasing the availability of health care and health professionals by improving community access to services through auxiliary health centers, including community health centers (Puskesmas) (Heywood and Choi, 2010).

However, uneven distribution of health facilities and labors brings an impact to the variation of healthcare coverage among provinces. The finding of this study is not much different from the results of inequality analysis of access to drinking water and sanitation across subnational regions done by Tin Afifah et al (2018). The wider gap found in the Eastern provinces of Indonesia which is known to be a geographically challenge. Another 
problem is the distribution of labor and facilities that are not evenly distributed throughout Indonesia. Most provinces in Java regions have easier access and sufficient number of health workers who are able to serve ANC 4+. To define responsibilities towards basic health services in local governments as well as to ensure the equity in access, Minister of Health has therefore launched a regulation number 43/2016 that consists of minimum standard of services in health sector, including the coverage of ANC 4+ (Ministry of Health of Indonesia, 2016). Given the growing number of private health provider, the standards in quality have been a great concern. Thus, further quality improvements at this provider are still upmost.

Another contributing factor is the government's commitment to improving the country's health system through the provision of social health insurance for the poor. Until the end of 2013, the main pro-poor social health insurance in Indonesia was Jamkesmas, financed by the central government. Jamkesmas was managed by the Ministry of Health and provided beneficiaries with free health services in Puskesmas and hospitals. Another type of insurance for the poor is Jamkesda, which is funded by the local government (province/district level). Such insurance programs enable the poor to gain access to health services (Achadi et al., 2015). In addition, an insurance scheme for maternal healthcare or Jampersal provides comprehensive maternal health service coverage to those who are not covered by Jamkesmas, Jamkesda, or any other health insurance scheme. The benefit packages of Jampersal include the coverage for antenatal care, delivery care, postpartum care for mother and newborn, and family planning (Achadi et al., 2015). An assessment study in two districts in Indonesia Garut and Depok - showed that nine in 10 (93.9\% and 96.3\%, respectively) women used Jampersal for antenatal check, increased slightly after three years of implementation (Achadi et al., 2015).

The findings of this study indicated that women's education was associated with ANC 4+ use. The likelihood of women using those recommended maternal healthcare services increased along with the increased educational attainment among women. Likewise, another study found increased odds of not attending ANC services among women with a low level of education (Titaley et al., 2010). Thaddeus and Maine (1994) suggested a theoretical framework explaining that social factor, such as education, as a key factor determining care-seeking decision and ultimately influencing the utilization of maternal healthcare services. Empowering women with formal education enhance women's capacity in recognizing their rights to health and making proper decisions for their health (Achia and Mageto, 2015). Women with a proper education also have capability to seek and obtain healthcare information and use it accordingly (Rai et al., 2012). Hence, higher schooling years may contribute to improving adequate maternal healthcare (Kurniati et al., 2018).

A 9-year compulsory education policy has increased length of school years as well as improved knowledge for both men and women. This also has an impact on women's capability in seeking health services for them. This is consistent with the results of the study conducted by Samarakoon and Parinduri (2015) which is shown that education increases contraceptive use and promotes reproductive health practices. Moreover, education allows women to gain literacy skills, enables them to process information, and develops their cognitive behavior. Therefore, when a woman is educated, she is able to take better care of herself (Duflo, 2012). Nonetheless, education may be insufficient to change deeply rooted societal attitudes or improve gender relations such as decision-making authority. Many parts of Indonesia are still governed by local tribes and norms (Kevane and Levine, 2003), which may hinder women to make household decisions by themselves. Moreover, patrilineal kinship in Indonesia often inhibits women's access their inheritance rights after marriage (Rammohan and Johar, 2009). The 2012 IDHS results show that having no permission from husband is reported as one reason for not accessing health care encountered by $5 \%$ women in Indonesia (Statistics Indonesia et al., 2013).

A great emphasis has been made on the state of health inequality in Indonesia in accordance with the spirit of SDGs to leave no one behind. On the one hand, ANC 4+ coverage is reaching better, and inequalities are decreasing, yet the main challenge in Indonesia is the high maternal mortality rate. Antenatal check is a tool for early detection of high risk and complications. It helps women to recognize delivery preparation in order to give birth safely. Various efforts have been made by the Ministry of Health, such as pregnancy class and birth 
preparedness program which allow women to plan for delivery, including referral system during pregnancy and delivery complications (Ministry of Health, 2015). However, the implementation of such programs has been continued to be a challenge for Indonesia to improve access to ANC services which requires increasing public health awareness.

\section{Conclusions}

The current study indicates improved social determinants of health in Indonesia, which at the same time also reduces health inequalities. Our findings imply the need for research solutions to reduce inequality in maternal health services, and to determine the factors responsible for the persistence of inequality in maternal health services, particularly recommended ANC services. Recognizing reproductive health as a basic right of women regardless of socio demographic and economic status is important in formulating national policy and programs to address inequality in maternal health service utilization. Thus, it is important to monitor utilization trends among disadvantaged groups and consider ways to incorporate adequate and quality service delivery with comprehensive financial scheme (universal health coverage). Promoting women's empowerment and awareness to their needs of maternal healthcare has another imperative strategy to reduce the cultural barriers.

\section{Acknowledgements}

The authors wish to express gratitude to the DHS Program for allowing authors to analyze the IDHS data sets.

\section{References}

Achadi, E.L., Achadi, A., Pambudi, E., and Marzoeki, P., 2014, A Study on the Implementation of JAMPERSAL Policy in Indonesia. Discussion Paper, the World Bank Group.

Achia, T. N. O., and Mageto, L. E., 2015,Individual and contextual determinants of adequate maternal health care services in Kenya. Women \& Health, 55(2), 203-226.

Adashi, E., Oey-Gardiner, M., Adriaansz, G., Berman, P., Goldenberg, R. L., Sastroasmoro, S., Shankar, A., and Soemantri, S., 2013, Reducing Maternal and Neonatal Mortality in Indonesia: Saving Lives, Saving the Future (Washington D.C.: The National Academic Press).

Afifah, T., Nuryetty, M.T., Musadad, D.A., Schlotheuber, A., Bergen, N. and Johnston, R., 2018, Subnational regional inequality in access to improved drinking water and sanitation in Indonesia: results from the 2015 Indonesian National Socioeconomic Survey (SUSENAS). Global Health Action, 11(sup1), 1496972-1496972.

Anwar, I., Nababan, H. Y., Mostari, S., Rahman, A., and Khan J. A. M.,2015, Trends and Inequities in Use of Maternal Health Care Services in Bangladesh, 1991- 2011. PLoS ONE, 10(3), e0120309.

Badan Pusat Statistik, 2016, Profil Penduduk Indonesia Hasil SUPAS 2015 (Jakarta: BPS).

Carroli, G., Villar, J., Piaggio, G., Khan-Neelofur, D., Gülmezoglu, M., and Mugford, M., 2001, WHO systematic review of randomised controlled trials of routine antenatal care, Lancet, 357(9268), 1565-70.

Chalmers, B., Mangiaterra, V., and Porter, R. 2001. WHO Principles of Perinatal Care: The Essential Antenatal, Perinatal, and Postpartum Care Course. Birth, 28, 202-207.

Corsi, D.J., Neuman, M., Finlay, J.E., and Subramanian, S.V., 2012, Demographic and health surveys: a profile. International Journal of Epidemiology, 41(6), 1602-1613.

Duflo, E., 2012, Women's empowerment and economic development.Journal of Economic Literature, 50(4), 1051-1079.

Heywood, P.F., and Harahap, N.P., 2009. Human resources for health at the district level in Indonesia: the smoke and mirrors of decentralization. Human Resources for Health, 7(1), 6.

Heywood, P. and Choi, Y., 2010, Health system performance at the district level in Indonesia after decentralization. BMC International Health and Human Rights, 10(1), 3.

Hosseinpoor, A.R., Bergen, N., and Schlotheuber, A., 2015, Promoting health equity: WHO health inequality monitoring at global and national levels, Global health action, 8(1), 29034. 
Hosseinpoor, A.R., Nambiar, D., Schlotheuber, A., Reidpath, D., and Ross, Z., 2016. Health Equity Assessment Toolkit (HEAT): software for exploring and comparing health inequalities in countries. BMC Medical Research Methodology, 16(1), 141.

Hosseinpoor, A.R., Bergen, N., Barros, A.J., Wong, K.L., Boerma, T., and Victora, C.G., 2016, Monitoring subnational regional inequalities in health: measurement approaches and challenges, International Journal for Equity in Health, 15(1), 18.

ICF International, 2012, Demographic and Health Survey Sampling and Household Listing Manual (Calverton, Maryland, U.S.A: ICF International).

Kevane, M., and Levine, D. I., 2003, Changing status of daughters inIndonesia. CIDER Working Paper No. C03-126

Kurniati, A., Chen, C.M., Efendi, F., and Berliana, S.M., 2018, Factors influencing Indonesian women's use of maternal health care services. Health Care for Women International, 39(1), 3-18.

Ministry of Health of Indonesia, 2015,Maternal and Child Health Book (Buku Kesehatan Ibu dan Anak) (Jakarta: Ministry of Health of Indonesia).

Ministry of Health of Indonesia, 2016,Minimum Standard of Health Services (Standar Pelayanan Minimal Bidang Kesehatan) (Jakarta: Ministry of Health of Indonesia).

Molina, H.F., Nakamura, K., Kizuki, M., and Seino, K., 2013, Reduction in inequality in antenatal-care use and persistence of inequality in skilled birth attendance in the Philippines from 1993 to 2008. BMJ Open, 3(6), e002507.

Nababan, H.Y., Hasan, M., Marthias, T., Dhital, R., Rahman, A., and Anwar, I., 2018, Trends and inequities in use of maternal health care services in Indonesia 1986-2012. International Journal of Women's Health, $10,11$.

Rahman, A., Nisha, M.K., Begum, T., Ahmed, S., Alam, N., and Anwar, I., 2017, Trends, determinants and inequities of 4+ ANC utilisation in Bangladesh. Journal of Health, Population and Nutrition, 36(1), 2.

Rai, R. K., Singh, P. K., and Singh, L., 2012, Utilization of maternal health care services amongmarried adolescent women: Insights from the Nigeria Demographic and Health Survey 2008. Women's Health Issues, 22(4), 407-414.

Rammohan, A., and Johar, M., 2009, The determinants of married women's autonomy in Indonesia. Feminist Economics, 15(4), 31-55.

Samarakoon, S., and Parinduri, R.A., 2015, Does education empower women? Evidence from Indonesia. World Development, 66, 428-442.

Simkhada, B., Teijlingen, E.R.V., Porter, M., and Simkhada, P., 2008. Factors affecting the utilization of antenatal care in developing countries: systematic review of the literature, Journal of Advanced Nursing, 61(3), 244-260.

Statistics Indonesia, National Family Planning Coordinating Board, Ministry of Health of Indonesia and ICF International, 2013,Indonesia Demographic and Health Survey 2012 (Jakarta: Statistics Indonesia).

Thaddeus, S., and Maine, D., 1994,Too far to walk: Maternal mortality in context. Social Science\& Medicine, 38(8), 1091-1110.

Titaley, C.R., Dibley, M.J., and Roberts, C.L., 2010. Factors associated with underutilization of antenatal care services in Indonesia: results of Indonesia Demographic and Health Survey 2002/2003 and 2007. BMC Public Health, 10(1), 485.

World Health Organization and Ministry of Health of Indonesia, 2017, State of Health Inequality: Indonesia (Geneva: World Health Organization). 